Western University Scholarship@Western

Psychology

Psychology

2000

\title{
Psychopathology of Altered States of Consciousness
}

Imants Barušs

King's University College, baruss@uwo.ca

Follow this and additional works at: https://ir.lib.uwo.ca/kingspsychologypub Part of the Psychology Commons

Citation of this paper:

Barušs, Imants, "Psychopathology of Altered States of Consciousness" (2000). Psychology. 8.

https://ir.lib.uwo.ca/kingspsychologypub/8 


\section{Psychopathology of Altered States of Consciousness}



Imants Barušs, King's College, University of Western Ontario, Canada

xperiences in altered states of consciousness have often been misunderstood as

ment of self-determination in favour of obedience to internal guidance. There are also problems of adjustment following transcendent, netogether, a mental health practitioner must lisbeing pathological when, in fact, they may be healthy or exceptionally beneficial. This appears to be, in part, because those who have had such experiences have sometimes made claims that contradict the predominant materialistic assumptions of much of Western psychology. For example, those who have had out-of-body experiences, possibly in the context of near-death experiences, sometimes have claimed to have had veridical perceptions of physical events that they should not have been able to have had through their sensory faculties. However, studies are summarized indicating that remote perception without sensory involvement can occur thereby emphasizing the importance of evaluating experiences in altered states of consciousness without restrictive preconceptions. In fact, from the point of view of transcendent states of consciousness, the normal waking state appears to be the pathological state. Clearly, however, not all experiences in altered states of consciousness are free of difficulties. In striving for transcendence, there is a large class of religious and spiritual problems that includes crises associated with spiritual awakening, cult participation and relinquishar-death and alien abduction experiences. Alten to her client, keep an open mind and develop a keen sense of discrimination when evaluating experiences in altered states of consciousness.

\section{Psychopathology of Altered States of Consciousness}

It is difficult to determine, sometimes, which behaviours should be considered consistent with normal human functioning and which should be considered pathological. This problem becomes compounded when we open the door to the further reaches of the mind, as we do in altered states of consciousness, and the distinction bet-

Author's note. The author thanks Solveiga Miezitis for an invitation to submit this paper to the Journal of Baltic Psychology and King's College for a paid sabbatical leave and research grants that made the writing of this paper possible.

Correspondence concerning this article should be addressed to Imants Barušs, Department of Psychology, King's College, 266 Epworth Ave., London, Ontario, Canada N6A 2M3. Electronic mail may be sent via Internet to baruss@uwo.ca.

Baltijas PSIHOLOGIJAS ŽURN $\bar{A} L S$ /Sēj. 1., Nr. 1,, 2000./ 
ween madness and normality becomes blurred. The purpose of this paper is to push our understanding further by considering what is pathology, normality and exceptional well-being in altered states of consciousness.

\section{Pathology, Normality, and Exceptional Well-Being}

Perhaps the first thing to note is that Western psychology is monophasic, that is to say, its subject matter is almost exclusively derived from a single state of consciousness, namely, the normal waking state. Furthermore, the normal waking state of consciousness is considered the optimal state. The presence of these characteristics of Western psychology, in conjunction with the prevalence of pathomorphism, the tendency to label psychological phenomena using pathological categories, means that experiences in altered states of consciousness have often been considered pathological when they may, in fact, be better labelled as normal or exceptionally beneficial. For example, shamanic journeying in indigenous cultures may be undertaken by a shaman in order to resolve a problem in her community and involves her entering an altered state of consciousness, experiencing separation from her body, travelling in a world different from ordinary reality, encountering spirits, searching for information or power that can resolve the problem, reentering her body and implementing the results of the journey in the community. While such experiences have often been labelled as symptoms of schizophrenia, careful comparison of shamanic journeying to schizophrenia reveals that they are not the same. In particular, for example, while someone with schizophrenia experiences disorganization and loss of control both for the onset of schizophrenic episodes and their contents, a shaman's journey is characterized by coherent imagery, control of the onset of the journey and partial control of the contents of experience (Walsh, 1995).

However, even if experiences in altered states of consciousness were not pathologized, they may nonetheless create disruption in a person's life and thus come to the attention of mental health professionals. Such disruption often occurs after neardeath experiences. These are psychological events that are sometimes reported by a person who has been close to death for some period of time. A person may report having experienced a feeling of peace, separation from her body, witnessing of events occurring within the vicinity of her body, encounters with deceased relatives or spiritual beings, the presence of a loving light, and a panoramic life review. Subsequently, a person's ideas about the nature of reality may be dramatically changed. She may come to believe that death is not the end of life, that our usual concerns about our material well-being are unimportant, and that the purpose of life is to love one another. Despite the overall positive nature of most near-death experiences, a person may experience anger and depression at having been brought back to life, career interruptions, fear of ridicule and rejection, alienation from one's relatives and acquaintances, and broken relationships including divorce from one's spouse. Many of these problems result from a person's inability to reconcile her altered sense of reality and changed values with the materialistic concerns of the people with whom she must interact (Greyson, 2000). 


\section{Psychology of Science}

Perhaps we should pause before proceeding. After all, psychology is a scientific enterprise and should psychologists entertain such manifestly absurd notions as travelling outside of one's body and encountering spiritual beings? No matter how positive such experiences may be for the individual for whom they have occurred, is there not something inherently wrong with having impressions that one has left one's body or that one has communicated with spirits? Indeed, psychologists write books such as How to Think Straight About Psychology (Stanovich, 2001) or, more provocatively, Psychobabble and Biobunk (Tavris, 2001) in which such notions are debunked in the name of scientific psychology. By all means, then, let us think straight and cut through the psychobabble of debunking itself using the methods and knowledge base of scientific psychology.

In contemporary cognitive psychology we have come to understand that human beings organize their experiences using cognitive structures called schemata. In particular, there are global schemata, called worldviews that are used for making sense of reality. Worldviews are mental constructions, ideas, beliefs, theories, and not themselves the reality for which they are interpretations. The currently dominant worldview in academia is that reality resembles a billiard table. All phenomena, including consciousness, result from the predictable interactions of tiny particles. But authentic science, of which scientific psychology is a part, is the pursuit of knowledge using whatever means one can invent to further one's understanding. The data acquired through one's investigations form the basis for one's theories. Not the other way around! Scientific theories change in response to evidence. Scientists discard and replace worldviews to reflect the results of their investigations. Thus we now know, from research in nuclear physics that matter is not made up of tiny billiard balls. Given that that is the case, there is no point in continuing to insist that all phenomena, including consciousness, result from predictable interactions of tiny particles. The billiard ball schema has become obsolete (Barušs, 1996).

What are we left with? What is the world really like? What is happening when someone says that she is outside her body? What is the nature of out-of-body perceptions? Are they purely products of the imagination or are they veridical? Is it possible for there to be visual perception without visual sensation? Is, in fact, the brain even necessary for the presence of consciousness? For a scientist, these are not matters to be decided by one's a priori beliefs, but research questions demanding empirical investigation and critical evaluation of the subsequent results. Is there any evidence at all to suppose that the world is other than it appears to be in its everyday manifestation?

\section{Occurrence of Anomalous Experiences}

Let us consider a case studied by Sabom (1998) of a woman in the United States who had a near-death experience. In order to excise an aneurysm in her brain, a surgical procedure known as hypothermic cardiac arrest was used. During this procedure, her body temperature was lowered to $60 \mathrm{deg}$ rees Fahrenheit, her heartbeat and breathing were stopped, and her brain activity was reduced to the point where there were 
no brain waves over the cerebral cortex and no auditory evoked potentials in response to 100 -decibel clicks, indicating a suppression of both cerebral and brain stem activity. Then the blood was drained from her head. In the past, different measures have been used for the presence of life, such as breathing, heartbeat, cerebral brain activity and brain stem activity. By any of these measures, the woman was dead. However, subsequent to the operation, she gave the following account of her experiences.

As the bone saw cut through her skull, the woman had the impression of leaving her body through the top of her head and looking down on the proceedings in the operating room. Her description of events, including, for example, her description of the bone saw, turned out to be correct even though she had been anaesthetized and her eyes taped shut. As the operation progressed through the hypothermic cardiac arrest, she had the impression of being transported as though she were going up in an elevator. She heard her grandmother calling her toward a light at the end of a tunnel. As she moved toward the light, it increased in size until she was overwhelmed by its brightness. She could discern not only her grandmother, but other relatives in the light. After some time with them, her uncle brought her back through the end of the tunnel. She could see her body. It looked dead. She did not want to get back into it, but she did. And then it hurt (Sabom, 1998). This case suggests the possibility of visual perception without visual sensation and the possibility of the continuation of consciousness without brain activity.

Ring and Cooper did a retrospective study of the near-death and out-of-body experiences of 31 blind people, 14 of whom had been blind from birth. The accounts of the near-death experiences of the 21 sub- jects who had had them are consistent with those of the sighted, including the presence of visual impressions for 15 of the 21 . For those who had had near-death or outof-body experiences, 9 of the 14 subjects who were congenitally blind reported visual impressions. Furthermore, some of those blind from birth who did not claim to have seen anything appear to have had visual elements but were unable to identify them as such because of their lack of experience with sight. For those blind from birth, the visual impressions in near-death experiences are striking given that their brains have never been developed for visual processing. Thus, for example, there are no visual images in the dreams of those who have been blind from birth, yet they were present in the near-death experiences of the congenitally blind participants in the study. There was insufficient information from sighted witnesses to conclusively corroborate the physical reality of the out-of-body perceptions of the blind that corresponded to physical events at the time of the experiences (Ring \& Cooper, 1997). Nonetheless, this study lends credence to the possibility of visual perception without the presence of visual sensations.

That remote perception, that is to say, perception without relevant sensory stimulation, is possible, has been demonstrated in a number of laboratory studies. The research sponsored by the United States government in the 1970s at Stanford Research Institute concerning remote viewing, the name given by Puthoff and Targ to anomalous perception at a distance, has become well known (Puthoff, 1996; Targ, 1996; Targ \& Katra, 1998). Subsequently, there has been a spate of popular books about the purported military applications of remote viewing (e.g., Schnabel, 1997; Mo- 
rehouse, 1996; Graff, 2000; Mandelbaum, 2000). A similar research program was taken up at the Princeton Engineering Anomalies Research Laboratory in the late 1970 s verifying the positive results of the earlier government-sponsored studies (Jahn \& Dunne, 1987; Nelson, Dunne, Dobyns \& Jahn, 1996). While participants in laboratory research concerning remote perception have usually been in a normal waking state of consciousness, there is some evidence to suggest that the accuracy of remote perception is increased in altered states of consciousness such as in a state of hypnosis (Radin, 1997) and, indeed, that anomalous events are more likely to occur in altered states of consciousness (Krippner \& George, 1986). I should add the caveat about hypnosis, that one has to be careful about making universal statements about its effects, given the varieties of phenomena to which the label of hypnosis has been attached and the increased propensity for confabulation induced by hypnosis (Kihlstrom, 1985; Frankel \& Covino, 1997).

A metanalysis of the extent to which anomalous events correspond to reality has been given by Radin (1997) and a review of the variety of anomalous experiences as such can be found in Cardeña, Lynn and Krippner (2000). Such summaries are beyond the scope of this paper. The point here is that one must pay attention to a person's account of her experiences without pathologizing them out-of-hand because they fail to conform to one's preconceptions about reality. This caution extends to the application of diagnostic categories to individuals. For example, according to the Diagnostic and Statistical Manual of Mental Disorders (Fourth Edition) "belief in clairvoyance" that is to say, belief that re- mote perception is possible, has been listed as a symptom of schizotypal personality disorder (American Psychiatric Association, 1994, p. 645). We have just shown that there are contexts in which experiences of remote perception may arise for someone and indicated that there is evidence to support the veridical nature of some remote perceptions. In other words, belief in clairvoyance is not, in and of itself, an illness, and hence, should not be treated as such. However this is not the same as saying that those who believe in clairvoyance necessarily experience veridical remote perceptions. Whether or not they do is a matter of investigation in each particular case. If someone believes that her remote perceptions correspond to reality when they do not, then this diagnostic criterion becomes applicable. But not otherwise.

\section{Pathology of Transcendence}

There is another domain in which there has been a tendency in the past toward pathomorphism, namely that of spiritual awakening, spiritual aspiration, self-transformation and the occurrence of transcendent states of consciousness. However, rather than being pathological, there is increasing evidence from research in the psychology of religion that participation in religious activities is beneficial for one's well-being, particularly during times of stress (Hood, Spilka, Hunsberger \& Gorsuch, 1996). In fact, because of its beneficial value for an individual, following upon Gardner's theory of multiple intelligences (1983), spirituality has been conceptualised as a form of intelligence, namely spiritual intelligence. Spiritually intelligent individuals are those who have the capacity for "transcendence," for entering "heightened spiritual sta- 
tes of consciousness," for investing everyday life with "a sense of the sacred," for using "spiritual resources to solve problems in living," and for "virtuous behavior" (Emmons, 1999, p. 164). For all its benefits, there are nonetheless difficulties that a person may encounter concerning spirituality. That spirituality is not pathological but that it can involve problems that may come to the attention of mental health practitioners is recognized by its inclusion in the section "Other Conditions That May Be a Focus of Clinical Attention" of the Diagnostic and Statistical Manual of Mental Disorders (Fourth Edition) as "V62.89 Religious or Spiritual Problem" (American Psychiatric Association, 1994, p. 685). What are some of these problems?

First of all, it is useful to make the distinction between religion and spirituality as the distinction between "adherence to the beliefs and practices of an organized religious institution" and a person's relationship to a purportedly existent transcendent reality without regard for religious creeds (Lukoff, Lu \& Turner, 1996, p. 234). Furthermore, for many people, the notion of spirituality includes the idea that one is on a journey of self-transformation in which specific practices such as meditation are used in order to experience transcendent states of consciousness in which existential questions are eventually to be answered (Barušs, 1996). There can be differences in the types of problems associated with religious observance and spirituality. For example, loss of one's faith in the religious doctrines that one has previously come to accept is a known religious problem (Lukoff, Lu \& Turner, 1996). However, while loss of faith may be a religious problem, it can also be a spiritual opportunity in the sense that it challenges a person to seek other sources of meaning. One way to understand the possibility of such reorientation, is to consider the cognitive, motivational and behavioural patterns of religiosity that have been measured in the past. The extrinsic orientation is characterized by an attitude of expediency, so that one's religious observances are superficial, not integrated into one's daily life, and used in the service of utilitarian needs such as social advancement. The intrinsic orientation is characterized by a commitment to a lived religiosity that provides one with meaning. Quest orientation is characterized by confrontation with existential issues, refusal to reduce the complexity of life, and an ongoing search for truth wherever it may be found. For those with a quest orientation, religious doubt is perceived to be a positive characteristic (Hood, Spilka, Hunsberger \& Gorsuch, 1996). In other words, one's loss of faith may result in the loss of intrinsic religiosity but open the door to quest and self-transformation. Interestingly enough, there has also been some movement in the other direction toward fundamentalism (Hood, Spilka, Hunsberger \& Gorsuch, 1996) perhaps from a need to reduce the burden of self-determination in the face of complexity (cf. Schwartz, 2000).

A crisis of any sort can sometimes become an existential crisis and precipitate a spiritual awakening. In such cases, regarding any difficulties that arise for a person as traditional psychopathologies can be harmful to her. Thus it is worthwhile to distinguish between regressive pathologies, which are characterized by an inability to function normally within those spheres within which normal functioning would be expected, and progressive pathologies, which arise from spiritual awakening or aspira- 
tion (Barušs, 1996). However, some spiritual events can be so overwhelming that they create disruptions in a person's ability to carry out the normal activities of her life. The term "spiritual emergence" has been used for reasonably benign manifestations of spiritual awakening, while the term "spiritual emergency" has been used for those that are more traumatic (Lukoff, Lu \& Turner, 1996, p. 238). In extreme cases, the designation "spiritual emergencies with psychotic features" has been used (Lukoff, 1996, p. 271).

One of the most dramatic forms of spiritual awakening, which responds poorly to classical Western psychiatric treatment but well to treatments specifically designed for it, is that of kundalini rising. In the Hindu tradition, kundalini is an energy that purportedly rises from the base of the spine to the head at some point in a person's spiritual development. In some cases, kundalini experiences appear to occur spontaneously or as a result of experimentation with yoga and breathing exercises (Scotton, 1996). Healthy symptoms of kundalini awakening can include the following:

sensations of energy, heat, or light that rush up the spine ... a perception of inner sound often likened to the buzzing of bees or the roar of a waterfall ... perception of intense white light ... a profound mystical experience which can include union with the divine, spiritual revelation, creative insight, prophetic or psychic visions, or a profound expansion of consciousness. (Kason \& Degler, 1994, p. 24)

However, a mental health practitioner may also see "bradycardia . . ., tachycardia, cool skin, flushed skin, spontaneous trance states, and spontaneous assumption of yogic postures." Treatment can include reassurance by the clinician and immersion in mundane tasks so as to "refocus atten tion on the ordinary world" (Scotton, 1996 p. 264).

\section{Inauthenticity}

Authenticity refers to a person being self determining and acting on the basis of he own understanding (Barušs, 1996). In so. me cases, spirituality can be inauthentic Spiritual defences are spiritual beliefs tha constrain a person so that she is unable tc express herself (Battista, 1996). However one has to be careful in how one deals witl spiritual defences. The natural tendencies that are constrained may themselves be destructive, such as tendencies toward drug abuse. Ideally one would like to encounte and transform one's natural tendencies in a constructive direction (Assagioli, 1988/ 1991; Ferrucci, 1982). Offensive spirituality refers to the imposition of oneself on others as someone who is spiritually developed, perhaps in order to coopt others for the maintenance of one's own spiritual identity (Battista, 1996). Clearly, there can also be a point at which self-righteous imposition of one's beliefs on others becomes offensive.

A more dangerous version of inauthenticity is one in which one abdicates responsibility for oneself to such an extent that there is no critical evaluation of the doctrines of the religious organization with which one has become affiliated. In fact, cults are characterized by the suppression of criticism of the fundamental beliefs of the cult's adherents (Barušs, 1996). Someone who dares to criticize a cult's dogma or its leaders risks being branded as being selfish or evil and subjected to efforts to correct her aberrant behaviour. If she persists in failing to comply with the expectations of 
the cult and leaves, she may be told that she has failed the test, that she is damned and that she has lost her opportunity for enlightenment. "Feeling totally alone, the ex-cult member [may experience] a turmoil of feelings: rage at the betrayal, fear of retaliation, horror at the possibility of perpetual damnation, grief at the loss of group support and affection, and shame at having been duped" (Deikman, 1996, p. 317). The attendant anxiety, depression and loss of self-confidence can bring ex-cult members into therapy.

These psychological dynamics of inauthenticity are not confined to recognizable cults such as the "The People's Temple... the Moonies and the Krishna devotees" but are found throughout our society such as in "large corporations, political groups, professional organizations, government bodies, and established religions" (Deikman, 1996, p. 321). For example, in the former Soviet Union, one's allegiance was supposed to be to communism, while in the Western world one is supposed to believe in capitalism, the unbridled accumulation of wealth, and rampant consumerism. The penalties for dissent may differ but the same reliance on coercive strategies can be identified (e.g., Cialdini, 1988). Even the scientific community is not exempt from cultlike behaviour in that there is a version of science known as scientism whereby one is expected to believe that the universe is essentially a physical place, that the fixed methods used in science are the only way in which anything can be known, and that all talk of spirituality and transcendence is nonsense (Barušs, 1996). Those who fail to acquiesce are sometimes nudged out of the system by being refused research funding, by rejection of their work for publication, and by being barred from hiring and promotion.

Indeed, our whole society can be thought of as a cult. Our normal waking state of consciousness can be regarded as pathological; as a state of consciousness in which we are labouring under the delusion that the everyday world is real when, in fact, it is not. And our "culture can be viewed as a vast conspiracy against selfknowledge and awakening in which we collude together to reinforce one another's defences and insanity" (Walsh, 1984, p. 58). According to this perspective, the waking state is not only not optimal, but a state of psychosis. Or at least, the normal waking state is an imperfect state superseded by more enlightened states. Now, these are dramatic claims. Is there any evidence for them? The superiority of transcendent states relative to the normal waking state is a contention that has been made by many of those who have experienced transcendent states of consciousness (e.g., MerrellWolff, 1994; 1995a; 1995b; Roberts, 1993; 1991; Wren-Lewis, 1988, 1994). In that regard, let us consider the experiences and philosophy of Merrell-Wolff.

Franklin Merrell-Wolff was born in 1887. After studies in mathematics and philosophy, and a year of teaching mathematics, he left a promising academic career in order to seek "a transcendent mode of consciousness that could not be comprehended within the limits of our ordinary forms of knowledge" (Merrell-Wolff, 1994, pp. 251-252). Twenty-four years of effort were rewarded in 1936 with the occurrence of two fundamental realizations whose effects persisted until his death in 1985. For Merrell-Wolff, the structure of events in transcendent states of consciousness is different from that within the everyday mode because the subject-object duality that cha- 
racterizes the manner in which we ordinarily think is superseded by consciousness without an object. There is an analogous change in the manner in which we can know something. Whereas there are only the two processes of sensory perception and rational thinking in our ordinary state of consciousness, a third mode of knowledge, characterized by identification with that which is known, becomes possible in transcendent states. There is a "shift in the base of consciousness" (Merrell-Wolff, 1994, p. 264) from oneself as implanted in the relative domain to being "forcibly removed and instantaneously transplanted into a supernal region" (Merrell-Wolff, 1994, p. 264). The everyday consciousness, which we assume to be real, turns out to be only apparently real, whereas the ground of being experienced in transcendent states of consciousness, which seems ephemeral from our everyday point of view, turns out to be actually real. Merrell-Wolff has used the analogy of a mirage in the desert to characterize this ontological inversion: "when one realizes a given condition is an illusion, it not only ceases to be, but ceases ever to have existed" (Merrell-Wolff, 1995a, p. 23).

Another pervasive manifestation of inauthenticity in the context of transcendence involves undue respect for subjective imagery that is regarded as arising from a superior level of being. Merrell-Wolff maintained that there is a mode of knowledge in addition to sensory perception and rational thought. The notion that we have superior modes of knowledge available to us is not an unpopular idea. In a 1986 survey, Barušs and Moore found that $55 \%$ of 334 academics and professionals who could potentially write about consciousness in the academic literature, agreed that "the- re are modes of understanding latent within a person which are superior to rational thought" (Barušs, 1990, p. 176). In a subsequent survey in 1996 at an international academic consciousness conference, $69 \%$ of 212 participants agreed with the same statement (Barušs \& Moore, 1998). For Merrell-Wolff, a superior mode of knowledge was activated in the course of a radical shift in the base of consciousness to a transcendent state. Another way of conceptualising the activity of a superior mode of knowledge has been to think of the perfusion of the normal waking consciousness or slightly altered states of consciousness, such as sleep, with insights from a superconscious domain (Assagioli, 1965). In other words, one may experience intuition. In unfolding one's potential as part of a process of self-transformation, one may deliberately seek to develop one's intuition and to pay attention to the guidance that it provides. The point here is not to discourage the effort to seek to acquire knowledge that is superior to rational thought but to point out the danger of uncritically trusting the mental images that are assumed to be that knowledge. There is also a related danger in becoming dependent on guidance thereby relinquishing one's capacity for creativity and self-determination, both of which are constituent qualities of a whole human being (Barušs, 1996).

\section{Dissociation}

There is a more explicit version of guidance that of channelling accompanied by trance. Channelling is the process by which a person believes herself to be acting as a channel for information from discarnate entities (Hanegraaff, 1996). And trance is the physiological and psychological state in 
which a person finds herself in the course of channelling (cf. Lambek, 1989). Clearly the definition of trance is circular. The problem is that the physiological, cognitive, emotional and behavioural dimensions of trance are not well understood (Walsh, 1995). In some cases, behaviour during trance has been identified as possession (Pattison, Kahan \& Hurd, 1986). On the other hand we could reconceptualise possession as dissociation. Someone who periodically manifests a constellation of behaviours, including her expressed self-identity, that is significantly different from her normal self, can be considered a candidate for Dissociative Identity Disorder (Kluft, 1996). Such reconceptualisation masks the real question: is the source of the channelled information external or internal (Barušs, 1996)? If we refrain from pathomorphism and set aside our preconceptions, that question has to be answered on a case by case basis. In many cases, the answer will remain unknown. And in many cases, it may be difficult to determine if the channelling is detrimental or beneficial to the person doing the channelling. However, to the extent that channelling is inauthentic, it may not be beneficial.

Some of the most enigmatic cases in altered states of consciousness are those of people claiming to have been abducted by aliens. Alien abduction experiences are characterized by "subjectively real memories of being taken secretly and/or against one's will by apparently non-human entities, usually to a location interpreted as an alien spacecraft ... where individuals are subjected to complex physical and psychological procedures" (Appelle, Lynn \& Newman, 2000, p. 254). The lifetime prevalence of alien abduction experiences has been estimated at between $.04 \%$ and $2.00 \%$ of the population (Miller, 1994). In other words, the prevalence of alien abduction experiences appears to be of the same order of magnitude as the lifetime prevalence of schizophrenia. If that is true, why don't we see these cases? The answer is that no one in her right mind would admit to a mental health practitioner that she believes that she has been abducted by aliens.

Noting that those in their right mind would not report alien encounters leads to the observation that "assessment by both clinical examination and standardized tests has shown that, as a group, abduction experients are not different from the general population in terms of psychopathology prevalence" (Appelle, Lynn \& Newman, 2000 , p. 268). Experients do, however, often have various physical and psychological problems, such as post-traumatic stress disorder, that appear to follow upon alien abduction experiences. And they appear to have more adjustment problems, including an unusually high rate of reported suicide attempts (Appelle, Lynn \& Newman, 2000). In addition to the failure to find psychopathology that could account for the abduction experience, Mack (1994) has given four additional arguments why abduction phenomena cannot be explained in psychiatric terms. First, reports from abductees in the United States who have had no contact with one another are nonetheless similar even with respect to details that have not been widely publicized. Second, there are physical signs associated with abduction experiences such as the physical absence of abductees during the time of abduction as reported by witnesses; "nosebleeds and various cuts, scoop marks, bruises and other complexly patterned skin lesions;" and implants found after abduction experiences, although none of these im- 
plants has been proved to be of non-biological origin. Third, abduction accounts occur in children who are too young for the psychiatric syndromes that are assigned to abduction experients. Fourth, abduction experiences have often been associated with sightings of unidentified flying objects either by the experient or other witnesses. In spite of those arguments, are alien abduction accounts just products of an overactive imagination? Perhaps. However, abductees are not high on hypnotisability or fantasy proneness as one would expect if these narratives were fantasies that had become indistinguishable from reality Appelle, Lynn \& Newman, 2000).

\section{Drug-Induced Phenomena}

Clearly, psychotropic drugs can induce or affect altered states of consciousness. Sometimes the effects are clearly pathological. Such is the case with Substance-Induced Sleep Disorders, which can result from intoxication with drugs such as alcohol, amphetamines, caffeine, cocaine, opioids, sedatives or other substances (American Psychiatric Association, 1994). For example, fluoxetine, a bicyclic antidepressant that inhibits the reuptake of serotonin, has been found to interfere with sleep. In one study of patients with major depression being treated with fluoxetine, all 41 participants had increased eye movements relative to their premedication condition according to at least one measure of oculomotor activity, 33 had increased muscle tension, and 14 had both increased eye movements and muscle tension in all sleep stages. Other studies have shown that these effects appear not to remit with termination of drug use indicating that fluoxetine may have long-term effects on the central nervous system (Armitage, Trivedi \& Rush, 1995). In the case of fluoxetine we have a treatment for psychopathology that itself produces psychopathology.

Other psychoactive drugs, notably some psychedelics, may have net beneficial effects. The purpose here is to discuss the neuropsychological effects of such drugs without regard for their legal status in different jurisdictions. In no way should what is said here be construed as endorsement for the use of illegal drugs. Not only is illegal drug use illegal, but potentially dangerous to the user, given that she is unlikely to know exactly what it is that she is ingesting. For example, the drug 4-methoxyamphetamine "has often been passed off as the love drug MDA [methylenedioxyamphetamine], though it is ten times more powerful and has killed many of its users" (Lavigne, 1999, p. 373).

An example of the beneficial effects of psychedelics was observed in what has become the most famous experiment in the psychology of religion, the Good Friday experiment. On April 20, 1962, ten divinity students were each given 30 milligrams of the psychedelic psilocybin before a Good Friday service. In evaluations done immediately after the drug experience and at six month and 24 to 27 year follow-ups, the investigators found that the experiences of the participants had had genuinely mystical features and that these experiences had been evaluated by the participants as having been important to their spiritual lives (Pahnke, 1963; Doblin, 1991). For example, Mike Young has said that he had found that "religious ideas that were interesting intellectually before ... [were now] connected to something much deeper than belief and theory" (quoted in Malmgren, 1994, p. 1F). According to Young, direct 
personal experience had allowed him to validate his religious ideas. While psychedelic experiences appear to have not had nearly the impact that some drug-free transcendent experiences can have (Smith \& Tart, 1998), they have, in some situations, promoted exceptional well-being.

\section{Criteria for Pathology}

Where does this leave us? How can we recognize psychopathology of altered states of consciousness? Shedding the problem of pathomorphism, our task becomes a difficult one. The unusual nature of a person's experiences is not proof of aberrance so that a mental health practitioner must listen with care to a client's account without restrictive preconceptions. Degree of adjustment is also not a reliable indicator of psychopathology since adjustment could be impaired even though the underlying pro- cesses are ones leading to eventual exceptional well-being as discussed, for example, with regard to religious or spiritual problems. Problems encountered in altered states of consciousness may be progressive rather than regressive so that traditional diagnostic categories and treatment strategies are inapplicable. Perhaps the concept of psychopathology is not a useful one for experiences in altered states of consciousness and, rather than trying to apply the schemata of pathology and health, a mental health practitioner can simply assist a client to develop in constructive directions irrespective of the nature of the experiences themselves. This requires a good understanding of the varieties of human experiences in altered states of consciousness and the development of a keen sense of discrimination.

\section{References}

American Psychiatric Association. (1994). Diagnostic and statistical manual of mental disorders (4th ed.). Washington, D. C.: Author.

Appelle, S., Lynn, S. J., \& Newman, L. (2000). Alien abduction experiences. In E. Cardeńa, S. J. Lynn \& S. Krippner (Eds.), Varieties of anomalous experience: Examining the scientific evidence (pp. 253-282). Washington, DC: American Psychological Association.

Armitage, R., Trivedi, M., \& Rush, A. J. (1995). Fluoxetine and oculomotor activity during sleep in depressed patients. Neuropsychopharmacology, 12(2), 159-165.

Assagioli, R. (1965). Psychosynthesis: A manual of principles and techniques.

\section{New York: Penguin.}

Assagioli, R. (1991). Transpersonal development: The dimension beyond psychosynthesis. London, England: HarperCollins. (Original work published 1988)

Barušs, I. (1990). The personal nature of notions of consciousness: A theoretical and empirical examination of the role of the personal in the understanding of consciousness. Lanham, MD: University Press of America.

Barušs, I. (1996). Authentic knowing: The convergence of science and spiritual aspiration. West Lafayette, IN: Purdue University Press.

Barušs, I., \& Moore, R. J. (1998). Beliefs about consciousness and reality of parti- 
cipants at 'Tucson II'. Journal of Consciousness Studies, 5(4), 483-496.

Battista, J. R. (1996). Offensive spirituality and spiritual defenses. In B. W. Scotton, A. B. Chinen \& J. R. Battista (Eds.), Textbook of transpersonal psychiatry and psychology (pp. 250-260). New York: BasicBooks.

Cardeńa, E., Lynn, S. J., \& Krippner, S. (Eds.). Varieties of anomalous experience: Examining the scientific evidence. Washington, DC: American Psychological Association.

Cialdini, R. B. (1988). Influence: Science and practice (2nd ed.). New York: HarperCollins.

Deikman, A. J. (1996). Treating former members of cults. In B. W. Scotton, A. B. Chinen \& J. R. Battista (Eds.), Textbook of transpersonal psychiatry and psychology (pp. 316-326). New York: BasicBooks.

Doblin, R. (1991). Pahnke's "Good Friday experiment": A long-term follow-up and methodological critique. The Journal of Transpersonal Psychology, 23(I), 1-28.

Emmons, R. A. (1999). The psychology of ultimate concerns: Motivation and spirituality in personality. New York: Guilford.

Ferrucci, P. (1982). What we may be: Techniques for psychological and spiritual growth through psychosynthesis. Los Angeles, California: Jeremy P. Tarcher.

Frankel, F. H., \& Covino, N. A. (1997). Hypnosis and hypnotherapy. In P. S. Appelbaum, L. A. Uyehara \& M. R. Elin (Eds.), Trauma and memory: Clinical and legal controversies (pp. 344-359). New York: Oxford University Press.

Gardner, H. (1983). Frames of mind: The theory of multiple intelligences. New York: Basic.
Graff, D. E. (2000). River dreams: The case of the missing general and other adventures in psychic research. Boston, Massachusetts: Element.

Greyson, B. (2000). Near-death experiences. In E. Cardeńa, S. J. Lynn \& S. Krippner (Eds.), Varieties of anomalous experience: Examining the scientific eviden$c e$ (pp. 315-352). Washington, DC: American Psychological Association.

Hanegraaff, W. J. (1996). New age religion and Western culture: Esotericism in the mirror of secular thought. Leiden, The Netherlands: E. J. Brill.

Hood, R. W., Jr., Spilka, B., Hunsberger, B., \& Gorsuch, R. (1996). The psychology of religion: An empirical approach (2nd ed.). New York: Guilford.

Jahn, R. G., \& Dunne, B. J. (1987). Margins of reality: The role of consciousness in the physical world. San Diego, California: Harcourt Brace Jovanovich.

Kason, Y., \& Degler, T. (1994). A farther shore: How near-death and other extraordinary experiences can change ordinary lives. Toronto, Ontario, Canada: HarperCollins.

Kihlstrom, J. F. (1985). Hypnosis. Annual Review of Psychology, 36, 385-418.

Kluft, R. P. (1996). Dissociative identity disorder. In L. K. Michelson \& W. J. Ray (Eds.), Handbook of dissociation: Theoretical, empirical, and clinical perspectives (pp. 337-366). New York: Plenum. Krippner, S., \& George, L. (1986). Psi phenomena as related to altered states of consciousness. In B. B. Wolman \& M. Ullman (Eds.), Handbook of states of consciousness (pp. 332-364). New York: Van Nostrand Reinhold.

Lambek, M. (1989). From disease to discourse: Remarks on the conceptualization of trance and spirit possession. In 
W. J. Lonner \& J. W. Berry (Series Eds.) \& C. A. Ward (Vol. Ed.), Cross-cultural research and methodology series: Vol. 12. Altered states of consciousness and mental health: A cross-cultural perspective (pp. 36-61). Newbury Park, California: Sage.

Lavigne, Y. (1999). Death dealers. Cocaine from Columbia, heroin from Asia, crack cocaine from the kid next door. The true story of how drugs hit the streets and who pays the price. Toronto, Ontario, Canada: HarperCollins.

Lukoff, D. (1996). Transpersonal psychotherapy with psychotic disorders and spiritual emergencies with psychotic features. In B. W. Scotton, A. B. Chinen \& J. R. Battista (Eds.), Textbook of transpersonal psychiatry and psychology (pp. 271-281). New York: BasicBooks.

Lukoff, D., Lu, F. G., \& Turner, R. (1996). Diagnosis: A transpersonal clinical approach to religious and spiritual problems. In B. W. Scotton, A. B. Chinen \& J. R. Battista (Eds.), Textbook of transpersonal psychiatry and psychology (pp. 231-249). New York: BasicBooks.

Mack, J. E. (1994). Why the abduction phenomenon cannot be explained psychiatrically. In A. Pritchard, D. E. Pritchard, J. E. Mack, P. Kasey \& C. Yapp (Eds.), Alien discussions: Proceedings of the $a b-$ duction study conference held at MIT, Cambridge, MA (pp. 372-374). Cambridge, Massachusetts: North Cambridge Press.

Malmgren, J. (1994, November 27). Tune in, turn on, get well? St. Petersburg Times, p. 1F.

Mandelbaum, W. A. (2000). The psychic battlefield: A history of the military-occult complex. New York: St. Martin's. Merrell-Wolff, F. (1994). Franklin Merrell-
Wolff's experience and philosophy: $A$ personal record of transformation and a discussion of transcendental consciousness. Albany, New York: State University of New York Press. (Consists of Pathways through to space and The philosophy of consciousness without an object: Vol. 1)

Merrell-Wolff, F. (1995a). Mathematics, philosophy \& yoga: A lecture series presented at the Los Olivos Conference Room in Phoenix, Arizona, in 1966. Phoenix, Arizona: Phoenix Philosophical Press.

Merrell-Wolff, F. (1995b). Transformations in consciousness: The metaphysics and epistemology. Albany, New York: State University of New York Press. (Consists of Introceptualism: The philosophy of consciousness without an object: Vol. 2) Miller, J. (1994). Envelope epidemiology. In A. Pritchard, D. E. Pritchard, J. E. Mack, P. Kasey \& C. Yapp (Eds.), Alien discussions: Proceedings of the abduction study conference held at MIT, Cambridge, MA (pp. 232-235). Cambridge, Massachusetts: North Cambridge Press.

Morehouse, D. (1996). Psychic warrior: Inside the CIA's Stargate program: The true story of a soldier's espionage and awakening. New York: St. Martin's.

Nelson, R. D., Dunne, B. J., Dobyns, Y. H., \& Jahn, R. G. (1996). Precognitive remote perception: Replication of remote viewing. Journal of Scientific Exploration, 10(1), 109-11.

Pahnke, W. N. (1963). Drugs and mysticism: An analysis of the relationship between psychedelic drugs and the mystical consciousness. Unpublished doctoral dissertation, Harvard University.

Pattison, E. M., Kahan, J., \& Hurd, G. S. (1986). Trance and possession states. In 
B. B. Wolman \& M. Ullman (Eds.), Handbook of states of consciousness (pp. 286-310). New York: Van Nostrand Reinhold.

Puthoff, H. E. (1996). CIA-initiated remote viewing program at Stanford Research Institute. Journal of Scientific Exploration, 10(1), 63-76.

Radin, D. I. (1997). The conscious universe: The scientific truth of psychic phenomena. New York: HarperCollins.

Ring, K., \& Cooper, S. (1997). Near-death and out-of-body experiences in the blind: A study of apparent eyeless vision. Journal of Near-Death Studies, 16(2), 101-147.

Roberts, B. (1991). The path to no-self: Life at the center. Albany, New York: State University of New York Press.

Roberts, B. (1993). The experience of noself: A contemplative journey (Rev. ed.). Albany, New York: State University of New York Press.

Sabom, M. (1998). Light \& death: One doctor's fascinating account of near-death experiences. Grand Rapids, Michigan: Zondervan.

Schnabel, J. (1997). Remote viewers: The secret history of America's psychic spies. New York: Dell.

Schwartz, B. (2000). Self-determination: The tyranny of freedom. American Psychologist, 55(1), 79-88.

Scotton, B. W. (1996). The phenomenology and treatment of kundalini. In B. W. Scotton, A. B. Chinen \& J. R. Battista (Eds.), Textbook of transpersonal psychiatry and psychology (pp. 261-270). New York: BasicBooks.

Smith, A. L. \& Tart, C. T. (1998). Cosmic consciousness experience and psychedelic experiences: A first person comparison. Journal of Consciousness Studies,

$$
\text { 5(1), 97-107. }
$$

Stanovich, K. E. (2001). How to think straight about psychology (6th ed.). Boston, Massachusetts: Allyn and Bacon.

Targ, R. (1996). Remote viewing at Stanford Research Institute in the 1970s: A memoir. Journal of Scientific Exploration, 10(1), 77-88.

Targ, R., \& Katra, J. (1998). Miracles of mind: Exploring nonlocal consciousness and spiritual healing. Novato, California: New World Library.

Tavris, C. (2001). Psychobabble \& biobunk: Using psychology to think critically about issues in the news (2nd ed.). Upper Saddle River, New Jersey: PrenticeHall.

Walsh, R. N. (1984). Journey beyond belief. Journal of Humanistic Psychology, 24(2), 30-65.

Walsh, R. (1995). Phenomenological mapping: A method for describing and comparing states of consciousness. The Journal of Transpersonal Psychology, 27(1), 25-56.

Wren-Lewis, J. (1988). The darkness of God: A personal report on consciousness transformation through an encounter with death. Journal of Humanistic Psychology, 28(2), 105-122.

Wren-Lewis, J. (1994). Aftereffects of near-death experiences: A survival mechanism hypothesis. The Journal of Transpersonal Psychology, 26(2), 107-115. 